\title{
Subseasonal Prediction of Significant Wave Heights over the Western Pacific and Indian Ocean Region 0
}

\author{
RAVI P. SHUKLA \\ Center for Ocean-Land-Atmosphere Studies, George Mason University, Fairfax, Virginia \\ JAMES L. KINTER \\ Center for Ocean-Land-Atmosphere Studies, and Department of Atmospheric, Oceanic, and Earth Sciences, \\ George Mason University, Fairfax, Virginia
}

(Manuscript received 21 April 2016, in final form 19 July 2016)

\begin{abstract}
The bias and skill of multi-week predictions of significant wave height (SWH) in the western Pacific and Indian Ocean (WP-IO) region are investigated. The WaveWatch III (WW3) model is forced with daily 10-m winds from the National Centers for Environmental Prediction (NCEP) Climate Forecast System, version 2 (CFSv2), retrospective forecasts (CFSR). Reforecasts using January and May initial conditions for the period 1999-2009 are considered. The main features of the climatological mean 10-m winds in weeks 1-4 are well captured by CFSv2, although the magnitude of the bias increases with lead time over much of the region in both the January and May cases. The CFSv2-WW3 system similarly captures the magnitude and spatial structure of SWH in weeks 1-4 well in both cases; however, the magnitude of the positive biases increases with lead time over the Southern Ocean (SO), the South China Sea, and the northwestern Pacific region in the January cases, and over SO in the May cases. The magnitude of the SWH variability grows weaker with lead time over SO, which may be related to the weaker interannual variability of 10-m winds in weeks $1-4$ over S0 in CFSR. During the first two forecast weeks, the temporal anomaly correlation skill of SWH is significantly higher than it is during weeks 3 and 4 in the WP-IO region. Based on a categorical forecast verification, the CFSv2-WW3 can predict rare events at these lead times.
\end{abstract}

\section{Introduction}

Substantial progress has been made over the past several decades in numerical weather prediction (NWP), as a result of advances in atmospheric observing systems, atmospheric models, high-end computing, and data assimilation methods. Climate simulations have likewise benefited from advances in computing and earth system observations (such as moored buoys and drifting profiling floats in the global ocean), as well as increasingly realistic

Supplemental information related to this paper is available at the Journals Online website: http://dx.doi.org/10.1175/ WAF-D-16-0078.s1.

Corresponding author address: Dr. Ravi P. Shukla, Center for Ocean-Land-Atmosphere Studies, George Mason University, 270 Research Hall, Mail Stop 6C5, 4400 University Dr., Fairfax, VA 22030.

E-mail: rshukla2@gmu.edu representations of the interactions between the atmosphere, ocean, and land surface in coupled climate models. Advances in climate prediction have also been driven by our improving understanding of the sources of seasonal-to-annual predictability, including El NiñoSouthern Oscillation (ENSO), soil moisture anomalies in transition regions and seasons, and the secular temperature trend associated with global climate change. The net result has been that model-based prediction systems can now provide credible predictions of the global climate up to few seasons in advance.

Between the time scales of NWP and global climate predictions, there is a gap at the subseasonal-to-seasonal (S2S) time scale. This gap has been identified as a high priority for both the research (e.g., NRC 2010) and operational (e.g., Hudson et al. 2011) prediction communities. Hoskins (2013) has noted that there is predictive potential at all time scales, including S2S, because of processes such as (i) persistent blocking states (Hoskins and Woollings 2015); (ii) interactions between the 
tropics and extratropics expressed, for example, in the dispersion of Rossby waves in response to tropical tropospheric heating (Hoskins and Karoly 1981); (iii) persistent ocean anomalies in both the tropics (e.g., Alexander 1992) and extratropics (e.g., Hartmann 2015); and (iv) persistent soil moisture anomalies that alter surface fluxes and atmospheric boundary layer stability (e.g., Koster et al. 2011; Guo et al. 2012). Considerable research into the Madden-Julian oscillation (MJO) has demonstrated S2S predictability beyond NWP time scales (Lin and Brunet 2009; Vitart 2014; Wang et al. 2014). There is also evidence that predictive information can be obtained from the state of the North Atlantic Oscillation (NAO; Scaife et al. 2014), as well as the influence of the stratosphere on the subseasonal behavior of the troposphere and surface (Baldwin and Dunkerton 2001; Scaife et al. 2005; Jung et al. 2010).

There are very few operational forecast products at this time scale, and the problem of subseasonal prediction in particular has only recently garnered attention at the national (e.g., see https://www.whitehouse.gov/the-pressoffice/2014/09/23/fact-sheet-president-obama-announcesnew-actions-strengthen-global-resil) and international [World Climate Research Programme (WCRP); WMO (2013)] levels. The demand for S2S predictions arises from a diverse set of information requirements in agriculture, transportation, energy resource management, and military operations. The U.S. Navy in particular has articulated requirements for forecast information at the multi-week time scale. For example, long-lead information about the potential for tropical cyclones and the statistics of significant wave heights are of critical importance for first-responder and humanitarian missions as well as fuel economy and other considerations of dayto-day naval operations. Recent studies (IPCC 2007) suggest that estimates of changes in wave height characteristics are required for the assessment of the effects of climate change on coastal erosion, shifts of storm tracks, and changes in storm frequency and intensity.

To provide an evaluation of the potential for delivering forecast information at lead times of 1-4 weeks, this paper summarizes an evaluation of subseasonal reforecasts produced using the second-generation Coupled Forecast System, version 2 (CFSv2; S. Saha et al. 2010, 2014). The reforecasts were originally generated to calibrate realtime forecasts with CFSv2, which is used by the National Oceanic and Atmospheric Administration (NOAA) to produce operational seasonal forecast guidance. The CFSv2 is also a component of the North American Multimodel Ensemble (NMME; Kirtman et al. 2014) that includes several other state-of-the-art coupled climate models for which reforecasts have been generated and which are used to produce real-time seasonal forecasts.
The CFSv2 and other models in the NMME have been shown to provide credible forecast information at the seasonal time scale. For example, Becker et al. (2014) found that most of the models in the NMME have fairly realistic spread and higher forecast skill for atmospheric variables (e.g., 2-m temperature and precipitation rate). Many previous studies have evaluated various aspects of the subseasonal-to-seasonal long-term simulation and prediction skill of both versions of the CFS model (Shukla and Kinter 2014; S. K. Saha et al. 2014; Goswami et al. 2014; Huang et al. 2015; Abhilash et al. 2015; Shukla and Huang 2015 and papers cited therein) and have identified some major issues in simulations and prediction skill.

Similar to NWP and seasonal climate prediction, models of the surface ocean have been used to predict surface wave activity to advise shipping and coastal interests (e.g., Tolman et al. 2002; Janssen et al. 2002). Chu et al. (2004) found that one such model, WaveWatch III (WW3) produces estimates of significant wave height (SWH) in the South China Sea (SCS) with relatively small errors comparable to the altimeter accuracy in that region. Mirzaei et al. (2013) forced WW3 with winds for 1979-2009 from the Climate Forecast System Reanalysis (CFSR; Saha et al. 2010) to simulate the wave climate in the southern SCS. Based on validation against altimeter data, they found that the simulated wave characteristics provide reasonable estimates of the wave climate in that region. Fan et al. (2012) compared monthly SWH results based on satellite altimeter measurements and WW3, finding good agreement in the magnitude and spatial distribution. Marshall et al. (2015) detected an MJO influence on the occurrence of daily low and high wave conditions across the tropics and in the North Pacific and North Atlantic, suggesting that intraseasonal variations of wave activity are potentially predictable both in the tropics and in the higher latitudes of the Pacific and Atlantic Oceans.

In the present study, the surface wind forecasts in the Indo-Pacific region from the CFSv2 reforecast have been applied to the WW3 ocean surface wave model (Tolman 2009), and the forecast skill at lead times of up to 4 weeks has been evaluated. In the following sections, we describe the experimental design, the verification dataset, and the analysis method in section 2, and we also describe the SWH climatology and prediction skill in the Indo-Pacific region in section 3. Results of categorical forecast skill are presented in section 4 . We provide a summary of the results and implications for applications in section 5 .

\section{Model descriptions, experimental design, and datasets}

This study employs a model of ocean surface waves, with input from a global, coupled climate forecast model. 
The ocean surface waves are predicted using WW3 (Tolman 2009), a fully spectral, third-generation ocean wind-wave model developed at the National Centers for Environmental Prediction (NCEP), analogous to the Wave Action Model (WAM; The WAMDI Group 1988; Komen et al. 1994). It has been widely validated against global network buoys and altimeter data and over globalscale and regional wave forecasts (Tolman 1998, 2002; Chu et al. 2004; Hanson et al. 2009; Chawla et al. 2009). WW3 also uses subgrids to better resolve islands in the simulations for improved estimation of refraction and wave energy reduction due to depth-induced breaking and blocking by obstructions (Tolman 2009).

The winds applied to WW3 are derived from the retrospective forecast data from the CFSv2 (S. Saha et al. 2014). The CFSv2, which became operational for seasonal prediction in 2011, is composed of interacting atmosphere, ocean, sea ice, and land surface component models. The atmosphere component model is a version of the NCEP Global Forecast System at T126 horizontal resolution (105-km grid spacing) with 64 vertical levels in a hybrid sigma-pressure coordinate. The ocean component model is the fourth-generation Geophysical Fluid Dynamics Laboratory (GFDL) Modular Ocean (and sea ice) Model (MOM4; Griffies et al. 2004). More details about the other components and the way in which the retrospective forecasts were generated are provided in S. Saha et al. (2014). The daily CFSv2 retrospective forecasts initialized in January and May for the period 1999-2009 were used in this study. These dates were chosen to obtain forecasts during the seasons when the MJO is active (January cases) and when the AustralAsian monsoon circulation is transitioning from the Australian region to Southeast Asia (May cases). The retrospective forecasts extending to 45-day lead time have initial conditions at 0000, 0600, 1200, and 1800 UTC every day for 1999-2009. These forecasts are part of a larger set spanning the period 1979-2010; however, daily surface wind data were only available for the 19992009 period. For each forecast, a set of 10-member lagged ensembles was generated to provide a more robust estimate of the forecasts for both January and May initial conditions (ICs) using the same procedure. For example, for the May cases, we used forecasts with ICs at 1800 UTC 30 April, 1200 UTC 30 April, 0600 UTC 30 April, 0000 UTC 30 April, 1800 UTC 29 April, 1200 UTC 29 April, 0600 UTC 29 April, 0000 UTC 29 April, 1800 UTC 28 April, and 1200 UTC 28 April to construct each 10-member lagged ensemble. The forecasts verifying on 1 May similarly have lead times of $6 \mathrm{~h}$ up to $60 \mathrm{~h}$. The retrospective forecasts at all lead times up to 42 days ( 6 weeks) are used to force WW3. The forcing of WW3 with CSFv2 10-m winds will be referred to as the CFSv2-WW3 system. The ensemble mean taken is the average of 10 forecast runs from each day in both January and May ICs to assess the performance of the CFSv2-WW3 system.

The CFSR (Saha et al. 2010) for the 11-yr period (1999-2009) is used for comparison in the present study. The CFSR is a third-generation reanalysis product that uses a global, coupled atmosphere-ocean-land surfacesea ice system to provide a first-guess state estimate in separate data assimilation steps for each component. We have generated daily values from the 6-hourly CFSR dataset and used the daily $10-\mathrm{m}$ winds to force WW3. For quantitative comparisons, the model outputs and observational data are first bilinearly interpolated onto a common grid of $1^{\circ} \times 1^{\circ}$ resolution, which is closer to the model resolution. We acknowledge that this simulated wave height by CFSR-WW3 is not a perfect observational estimate; however, this choice enables a more consistent comparison.

We configured WW3 over a domain covering a portion of the western Pacific and Indian Ocean (WP-IO; $\left.60^{\circ} \mathrm{S}-40^{\circ} \mathrm{N}, 80^{\circ} \mathrm{E}-180^{\circ}\right)$ as in Lopez and Kirtman (2016) with a grid resolution of $1^{\circ} \times 1^{\circ}$, including implementing the appropriate bathymetry, land-sea mask, and obstruction grids. From the daily SWH data, weekly mean data were generated for both January and May cases (i.e., 1-7 January, 8-14 January, etc.). Weekly mean wave height anomalies were derived for each week with respect to that week's climatology.

\section{Results}

\section{a. The spatial distribution of 10-m wind}

Before discussing the climatology and subseasonal predictability of SWH, it is necessary to assess how well CFSv2 predicts the mean characteristics of $10-\mathrm{m}$ wind. The following convention is adopted: $\mathrm{Wk} n$ refers to the weekly mean in the $n$th week of the month; for example, $\mathrm{Wk} 1$ is the average of the first week (1-7 January for January cases and 1-7 May for May cases). In addition, Wkn- $m$ refers to the average of weeks $n$ through $m$; for example, Wk2-4 is the average of weeks 2, 3 and 4. Both the climatology and bias of predicted $10-\mathrm{m}$ wind were analyzed for weeks 1-4 (Wk1-Wk4) over WP-IO in both January and May cases. Figure 1 shows the climatological mean and bias of 10-m wind speed (colored shading) and direction (unit vectors) for Wk1-Wk4 in the observations (CFSR) and CFSv2 for the January cases. There are several important features of the observed 10-m wind to note in Wk1 (Fig. 1a). First, the wind is primarily westerly over the Southern Ocean (SO), is strongest in the region $50^{\circ}-45^{\circ} \mathrm{S}, 81^{\circ}-122^{\circ} \mathrm{E}$, has a peak magnitude of $9 \mathrm{~m} \mathrm{~s}^{-1}$, and has easterly wind 

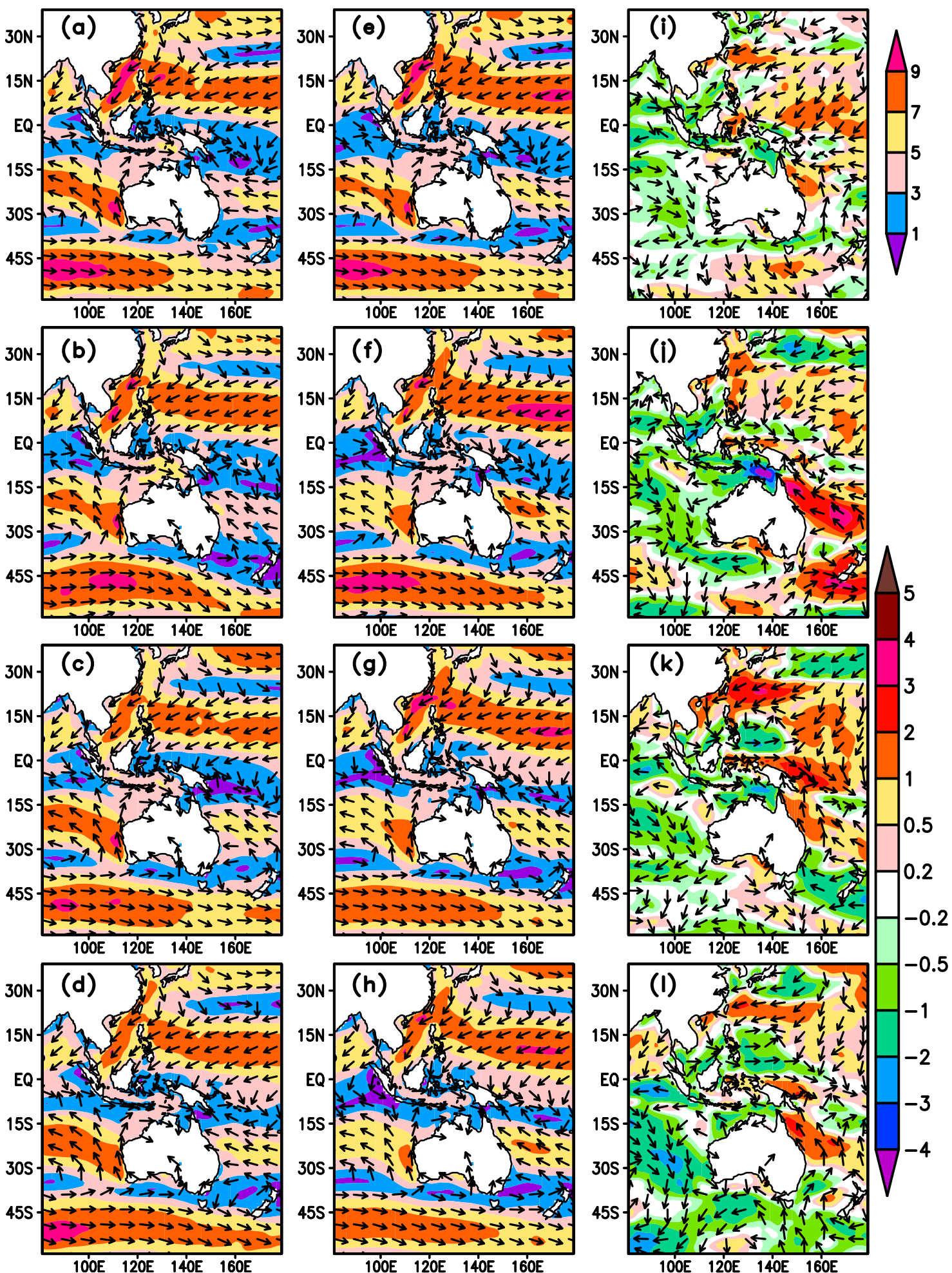

FIG. 1. The spatial distributions of 10-m wind speed (colored shading) and direction of 10-m wind (unit vectors) for Wk1 of January in (a) CFSR and (e) CFSv2-WW3. Color denotes magnitude of 10-m winds and direction of $10-\mathrm{m}$ winds is indicated by the unit arrow. The scale for the magnitude $\left(\mathrm{m} \mathrm{s}^{-1}\right)$ is shown at the top right. (i) The climatological biases relative to the observations for 10-m wind (colored shading) and direction of $10-\mathrm{m}$ wind (unit vectors). The scale for the biases $\left(\mathrm{m} \mathrm{s}^{-1}\right)$ is shown at the bottom right. (b)-(d) As in (a), but for Wk2, Wk3, and Wk4 of January, respectively. (f)-(h) As in (e) but for Wk2, Wk3, and Wk4 of January, respectively. (j)-(l) As in (c), but for $\mathrm{Wk} 2, \mathrm{Wk} 3$, and $\mathrm{Wk} 4$ of January, respectively. 
over the north-central western Pacific Ocean (NCWP), South China Sea (SCS), and Bay of Bengal (BOB) with a peak magnitude of $7 \mathrm{~m} \mathrm{~s}^{-1}$ in SCS and NCWP. During Wk2-Wk4 (Figs. 1c,d), the spatial patterns of the weekly mean $10-\mathrm{m}$ wind do not change dramatically. Qualitatively, the amplitude and pattern of the flow over each of the subregions listed above are well predicted by the CFSv2 (Figs. 1e-h) in Wk1-Wk4, although the Wk1 prediction is superior to those in $\mathrm{Wk} 2-\mathrm{Wk} 4$. The forecast bias (forecast minus observation) is shown in Figs. 1i-l. Quantitatively, the model has a negative bias over the BOB, SCS, and SO regions, with a deficit of up to $1 \mathrm{~m} \mathrm{~s}^{-1}$, and a positive bias in the NCWP region and southern Pacific Ocean in Wk1 (Fig. 1e). The magnitude of the bias increases with lead time (Figs. 1j-11).

Figure 2 depicts the climatological mean and bias of 10- $\mathrm{m}$ wind speed (colored shading) and direction of $10-\mathrm{m}$ wind (unit vectors) for the May cases. In May the observed Wk1 10-m wind over WP-IO (Fig. 2a) is primarily westerly over the $\mathrm{BOB}$ and $\mathrm{SO}$, is strongest in the region $50^{\circ}-45^{\circ} \mathrm{S}, 81^{\circ}-179^{\circ} \mathrm{E}$, has a peak magnitude of $9 \mathrm{~m} \mathrm{~s}^{-1}$, and is easterly over the southern Indian Ocean (SIO) with a peak magnitude of $3-7 \mathrm{~m} \mathrm{~s}^{-1}$. The magnitude of the easterly wind over the SCS region and the northern western Pacific is weak. Qualitatively, the magnitude and pattern of the flow over the SO, SIO, and $\mathrm{BOB}$ regions in $\mathrm{Wk} 1-\mathrm{Wk} 4$ are well predicted by the CFSv2 (Figs. 2e-h) in the May cases. As in the January cases, the Wk1 prediction by CFSv2 is superior to those for Wk2-Wk4. Quantitatively, the model has systematic biases in $\mathrm{Wk} 1-\mathrm{Wk} 3$, including a positive bias over $\mathrm{BOB}$ and the northern and southern regions of the western Pacific Ocean, mainly around $23^{\circ} \mathrm{N}$ and $45^{\circ} \mathrm{S}$, respectively, and a negative bias in the SIO and NCPW, mainly around $33^{\circ} \mathrm{S}$ and $14^{\circ} \mathrm{N}$, respectively.

Based on this analysis, we conclude that CFSv2 produces credible forecasts of the magnitude and direction of low-level winds in Wk1-Wk4, and, because the WW3 simulation of ocean surface winds strongly depends on the direction and magnitude of $10-\mathrm{m}$ winds, CFSv2 is a suitable source of wind predictions with which to force a wave model (Tolman 1998, 2002, 2009; Young 1999; Woolf et al. 2002; Vinoth and Young 2011).

\section{b. The spatial distributions of significant wave height}

In this section, we evaluate the characteristic features of the SWH climatology and variability during Wk1Wk4 over the WP-IO region predicted by CFSv2-WW3 in both January and May cases as compared to the same features obtained from forcing WW3 with CFSR (CFSR-WW3). Figure 3 shows the weekly mean observed (Figs. 3a-d) and predicted (Figs. 3e-h) SWHs for January cases in this broader area. The corresponding model biases (CFSv2-WW3 minus CFSR-WW3) are shown in Figs. 3i-l. The SWHs are strongest in the region $50^{\circ}-45^{\circ} \mathrm{S}, 81^{\circ}-122^{\circ} \mathrm{E}$, with a peak amplitude of $3 \mathrm{~m}$, and strongest in the SO, SIO, SCS, and NCWP between $15^{\circ}$ and $35^{\circ} \mathrm{N}$, with a peak amplitude of $3 \mathrm{~m}$ in $\mathrm{Wk} 1$. During Wk2-Wk4 (Figs. 3c,d), the magnitude and spatial patterns of the weekly mean SWH do not change dramatically, although a peak in amplitude of SWH in the SO occurs in Wk2. Consistent with Chu et al. (2004), the magnitude of SWH over the SCS region in CFSRWW3 is $1.8-2.4 \mathrm{~m}$ in Wk1-Wk4. Hereinafter, the SWH produced by CFSR-WW3 is referred to as the "observed SWH" insofar as that is the most direct comparison, and the CFSR-WW3 is a reasonably good proxy for remotely observed SWHs. Qualitatively, the magnitude and spatial pattern of SWH over the SO, SIO, NCWP, and SCS during Wk1-Wk4 are well predicted by the CFSv2-WW3 (Figs. 3e-h), with maxima in the Northern Hemisphere around $33^{\circ} \mathrm{N}$ and the Southern Hemisphere at about $50^{\circ} \mathrm{S}$ in both the observed and CFSv2-WW3 results. The model has a positive bias over the SO, SCS, and NCWP regions, with SWHs up to 0.1$0.3 \mathrm{~m}$ higher than for CFSR-WW3 during Wk1 (Fig. 3i). As for wind forecasts, the magnitude of the SWH bias increases with lead time (Figs. 3j-1) over these regions.

The observed and predicted SWH climatological means for Wk1-Wk4 in WP-IO and the corresponding model biases for May cases are shown in Fig. 4. The SWH is largest in the region spanning $50^{\circ}-45^{\circ} \mathrm{S}, 81^{\circ}-$ $179^{\circ} \mathrm{E}$, with peak amplitudes of $3.3-3.6 \mathrm{~m}$ in $\mathrm{Wk} 1-\mathrm{Wk} 4$ of May (Figs. 4a-d). The magnitude of SWH in the BOB region during $\mathrm{Wk} 2$ and $\mathrm{Wk} 3$ is around $1.8 \mathrm{~m}$, higher than in Wk1 or Wk4. Qualitatively, the CFSv2-WW3 results capture the main features of the observed SWH, including the locations and magnitudes of the maxima. However, the difference map (Fig. 4i) for Wk1 shows that, unlike for the January cases in which the $\mathrm{Wk} 1$ bias was mostly positive in the WP-IO, the model bias is mostly negative except in the high-latitude SO region and in the shallow seas between Australia and Indonesia. The negative bias diminishes, to be replaced by a positive bias nearly everywhere by Wk4.

Figure 5 shows the interannual standard deviation of weekly mean SWH anomalies in January cases over WP-IO. In the observed (Figs. 5a-d), there is considerable variability in the regions of large $\mathrm{SWH}$, for example, in the SO, SCS, and northwestern Pacific regions. The interannual variability of $\mathrm{SWH}$ anomalies during $\mathrm{Wk1}$ (Fig. 5a) are well captured by CFSv2-WW3 (Fig. 5e) but the amplitude of the SWH variability is lower than observed over a portion of the SO region (Fig. 5i) in Wk1. The magnitude of the variability of the predicted SWH diminishes with lead time, so that the bias significantly 

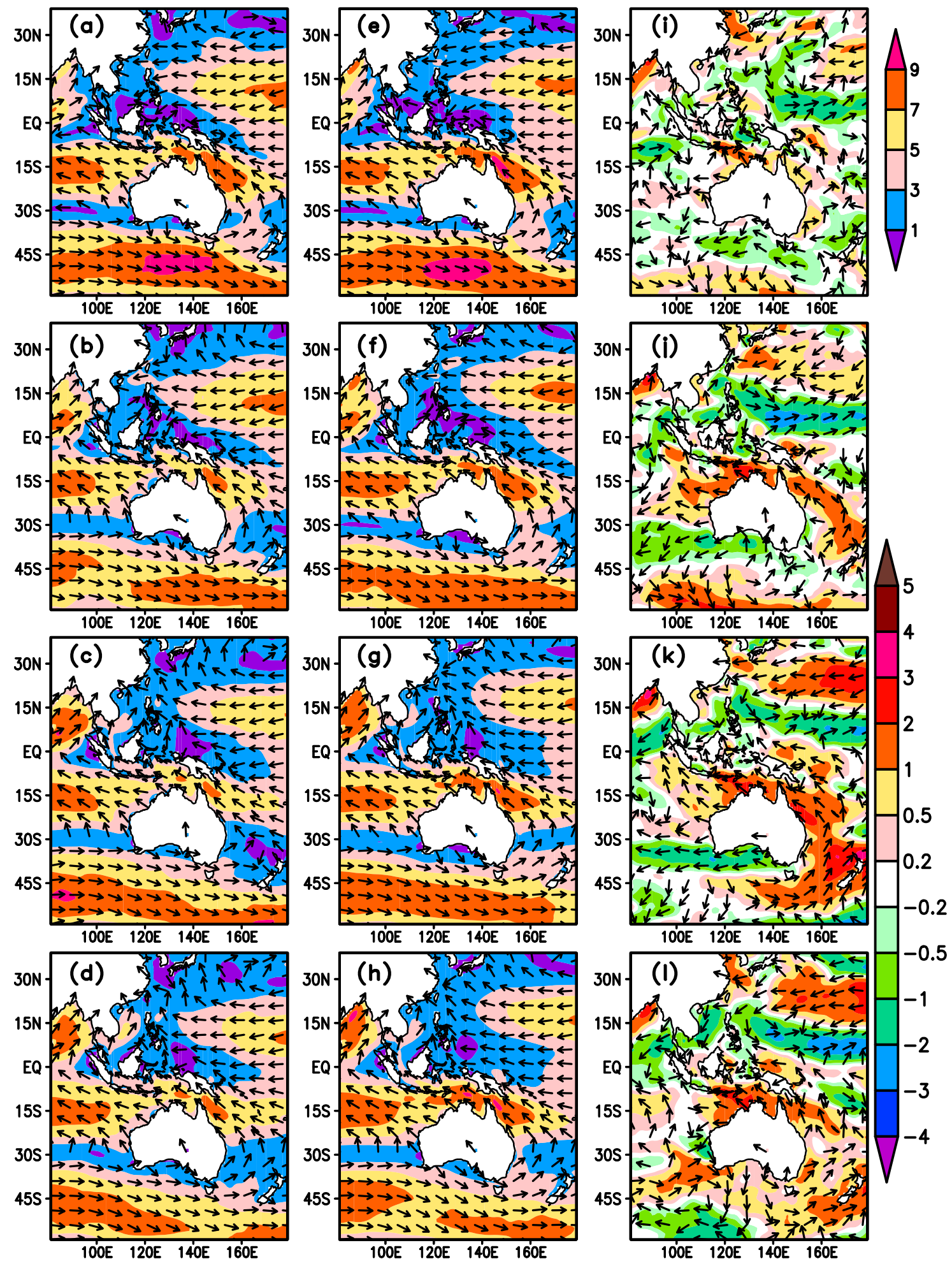

FIG. 2. As in Fig. 1, but for the May cases. 

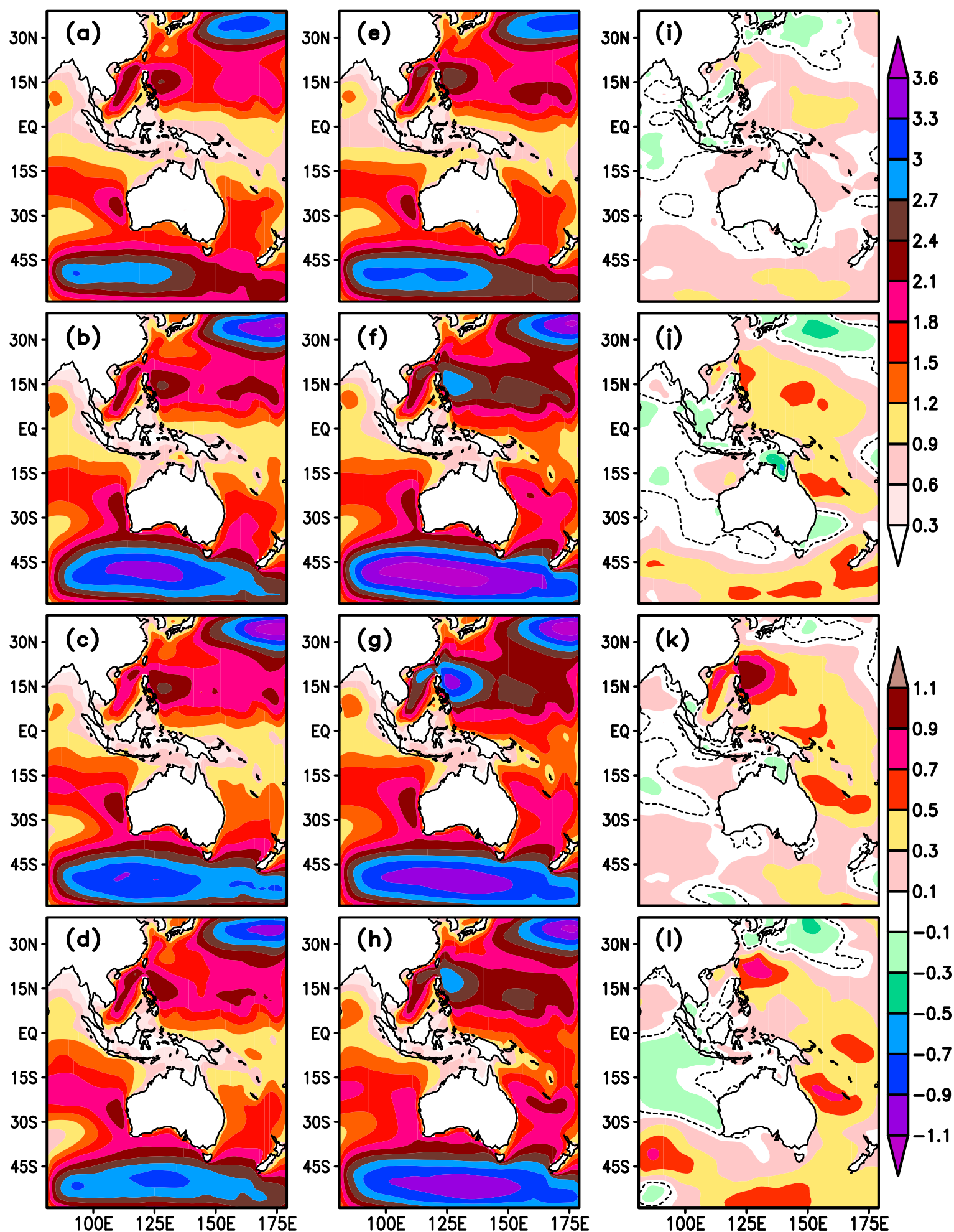

FIG. 3. The spatial distributions of SWH (colored shading) for Wk1 of January in (a) CFSR and (e) CFSv2-WW3. The scale for the magnitude $(\mathrm{m})$ is shown at top right. (i) The climatological biases relative to observations for wave height (colored shading). The scale for the biases (m) is shown at bottom right. (b)-(d) As in (a), but for Wk2, Wk3, and Wk4 of January, respectively. (f)-(h) As in (e), but for $\mathrm{Wk} 2, \mathrm{Wk} 3$, and Wk4 of January, respectively. (j)-(1) As in (c), but for Wk2, Wk3, and Wk4 January, respectively. 

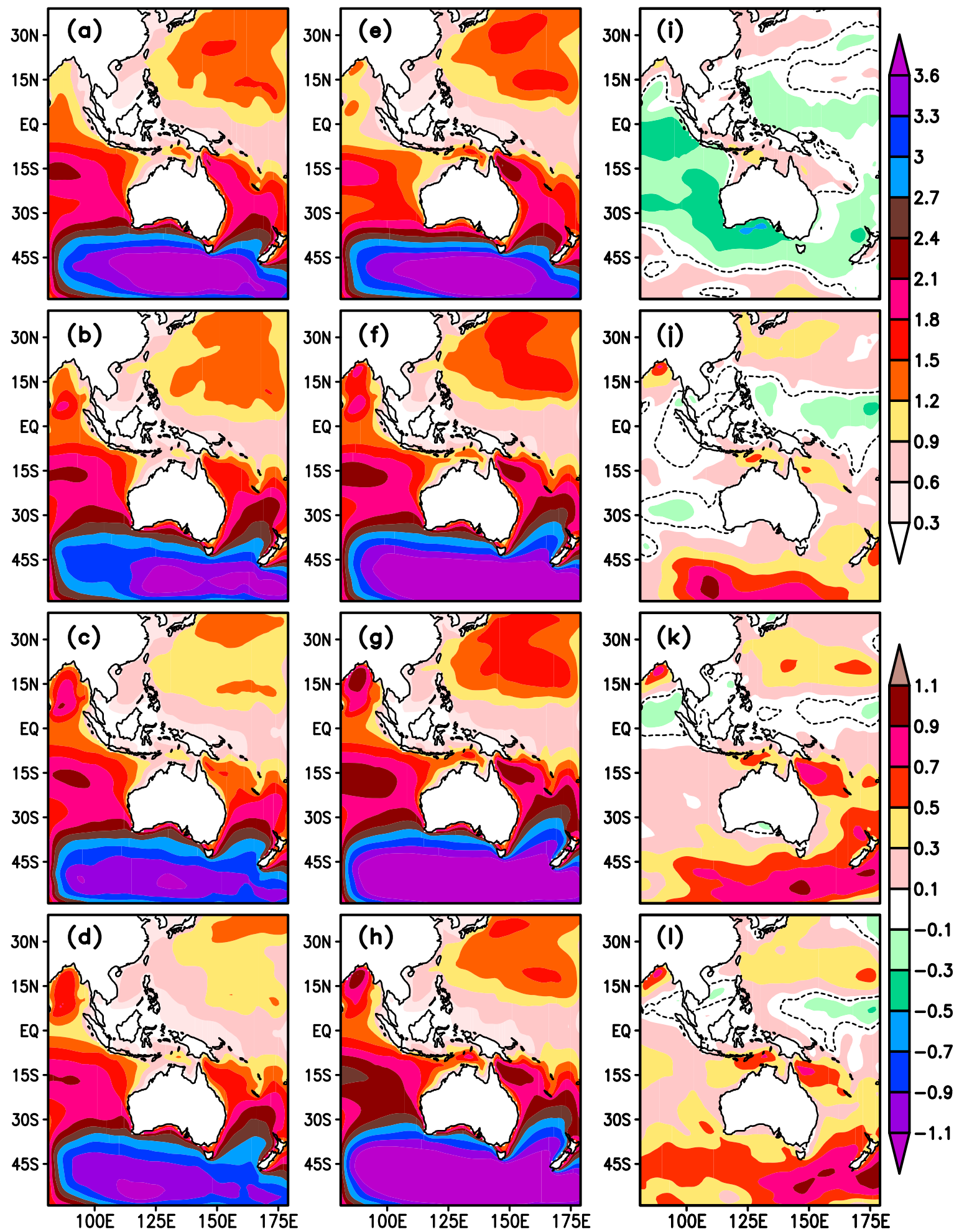

FIG. 4. As in Fig. 3, except for the May cases. 

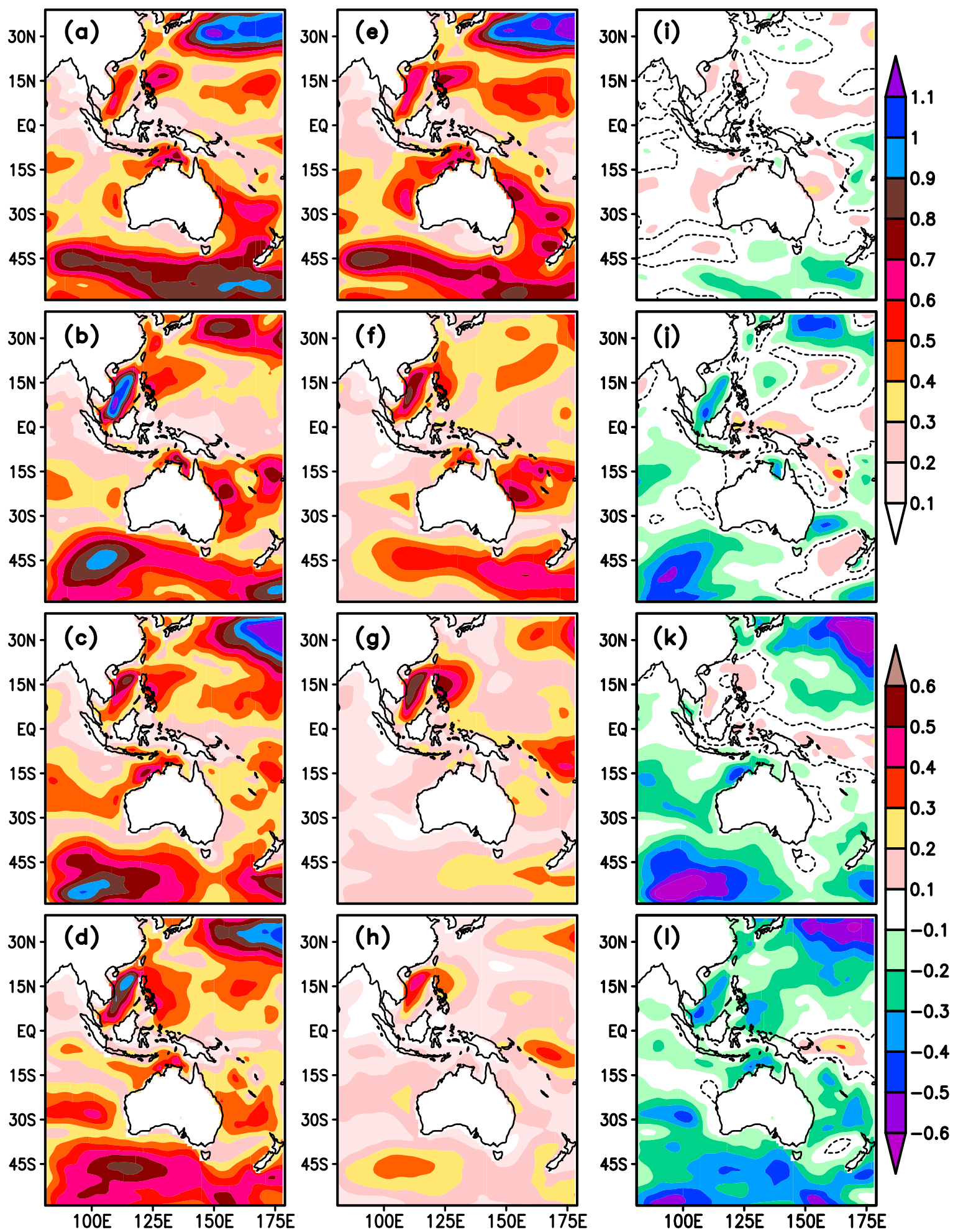

FIG. 5. Interannual standard deviation of SWH anomalies for Wk1 of January in (a) CFSR and (e) CFSv2-WW3. The scale for the magnitude $(\mathrm{m})$ is shown at top right. (i) Interannual standard deviation of Wk1 of the January SWH anomaly difference between CFSv2WW3 and the observations. The scale for the biases (m) is shown at bottom right. (b)-(d) As in (a), but for Wk2, Wk3, and Wk4 of January, respectively. (f)-(h) As in (e), but for Wk2, Wk3, and Wk4 of January, respectively. (j)-(l) As in (c), but for Wk2, Wk3, and Wk4 January, respectively. 
increases with lead time (Figs. 5j-1) over the SO, SIO, and northern western Pacific regions, eventually reaching a SWH variability deficit of up to -0.5 to $-0.6 \mathrm{~m}$.

The interannual standard deviation of the weekly mean SWH anomalies in the May cases is shown in Fig. 6. In the observations (Figs. 6a-d), there is large SWH variability in the regions of large SWH, for example, in the SO and BOB regions. The model captures the high variability over the SO region during Wk1 (Fig. 6e), although the predicted variability is slightly weaker than observed over the SIO and SO regions. The magnitude of the SWH variability diminishes with lead time, as in the January cases, and the bias significantly increases during $\mathrm{Wk} 2$ and $\mathrm{Wk} 3$ (Figs. $5 \mathrm{j}-1$ ) over the SO and SIO regions, with an SWH variability deficit of up to -0.5 to $-0.6 \mathrm{~m}$.

The weekly interannual standard deviation of the magnitude of $10-\mathrm{m}$ wind anomalies in both the January and May cases is lower in the CFSv2 retrospective forecasts than in CFSR, and the discrepancy grows with lead time (not shown). It is reasonable to conclude that weak variability of $10-\mathrm{m}$ wind in the CFSv2 forecasts is a major cause of the weak interannual variability of weekly mean SWH in WP-IO in both the January and May cases.

\section{c. Temporal anomaly correlation skill and root-mean-square error of $\mathrm{SWH}$}

The most basic and commonly used skill metric to quantify climate forecasts is the anomaly correlation between the ensemble mean of the model output and observed quantities (Barnston et al. 2010). This section documents the overall temporal prediction skill for Wk1-Wk4 SWH predicted by the CFSv2-WW3 model, initialized in January (Figs. 7a-d) and May (Figs. 7e-h). As a reviewer has suggested, we have employed a 1-yr cross-validation window to calculate the correlation coefficient. We have only displayed the correlations that are above or at the $90 \%, 95 \%, 98 \%$, and $99 \%$ significance levels. For both January (Fig. 7, left panels) and May (Fig. 7, right panels) cases, the temporal anomaly correlation (TAC) of the SWH anomalies decreases with lead time. During the first 2 weeks, the TAC is significantly higher and also comparable in both the January and May cases. There are some differences, however, in Wk2 between the January and May cases. The TAC over the central northwestern Pacific, mainly around $15^{\circ} \mathrm{N}$ in the January cases (Fig. $7 \mathrm{~b}$ ), is insignificant, in contrast to the May cases (Fig. 7f). The TACs for Wk3 and Wk4 (Figs. 7c,d,g,h) are lower than in the first 2 weeks (Figs. 7a,b,e,f) in both the January and May cases. The TAC for Wk 3 is greater than 0.5 for some areas in both the January and May cases, but it is less than 0.5 for most areas in Wk4 in both the January and May cases. The TAC for Wk3 (Fig. 7c) in the January cases is above 0.5 in the SCS, the northwestern Pacific Ocean (mainly $2^{\circ}-15^{\circ} \mathrm{N}, 123^{\circ}-150^{\circ} \mathrm{E}$ ), the southwestern Pacific Ocean $\left(30^{\circ} \mathrm{S}-14^{\circ} \mathrm{N}, 160^{\circ}-179^{\circ} \mathrm{E}\right)$, and the SO $\left(46^{\circ}-35^{\circ} \mathrm{S}, 81^{\circ}-110^{\circ} \mathrm{E}\right)$. During May, the TAC for Wk3 (Fig. 7g) is significant in the Bay of Bengal, the central northwestern Pacific, and the southern Indian Ocean $\left(20^{\circ} \mathrm{S}-15^{\circ} \mathrm{N}, 100^{\circ}-121^{\circ} \mathrm{E}\right)$. The TAC for $\mathrm{Wk} 4$ is significant only in the southern Indian Ocean in January (Fig. 7d) and in the SCS in May (Fig. 7h).

The forecast performance of the SWH anomaly is also assessed using the temporal root-mean-square error (RMSE) for Wk1-Wk4 in both January (Figs. 8a-d) and May (Figs. 8e-h) cases. The RMSE is lower in Wk1 than in other weeks in both the January (Fig. 8a) and May (Fig. 8e) cases. We have found that there are large increases in RMSE from Wk1 to Wk2 in the SO in both January and May. The RMSEs for $\mathrm{Wk} 3$ and $\mathrm{Wk} 4$ (Figs. 8c,d,g,h) are higher than for the first 2 weeks (Figs. 8a,b,e,f) in both the January and May cases. The RMSE is generally higher over the northwestern Pacific Ocean for Wk2-Wk4 in January (Figs. 8b-d) in comparison to May (Figs. $8 \mathrm{f}-\mathrm{h}$ ). Based on the TACs and RMSEs of the SWH anomalies, the SWH forecast skill is generally higher in the tropics than in the subtropics.

Based on reviewers' suggestions, we have conducted 3-month reforecast experiments using an updated version of CFSv2 (Huang et al. 2015; Shukla and Huang 2015), referred to herein as CFSv2_rev. The reforecasts were made using ocean initial conditions (OICs) from the CFSR (Saha et al. 2010) and the NCEP Global Ocean Data Assimilation System (GODAS; Behringer 2005) for the period 1979-2009. For each OIC, four ensemble members were generated by using atmospheric and land surface initial conditions (AICs and LICs) taken from the instantaneous fields at 0000 UTC over the first 4 days in January and May of each year. The total number of ensemble members was $8-2$ (OICs) $\times 4$ (AIC/LICs), for both the January and May cases. Using the more extensive set of reforecasts for the January and May cases over the period 1979-2009, we have run the WW3 model to generate ocean surface waves. For the longer period of the reforecasts, the magnitude and spatial structure of the biases of SWH in Wk1-Wk4 (see Figs. S1 and $\mathrm{S} 2$ in the online supplement to this article) in both the January and May cases are similar to the results for 19992009 (Figs. 3 and 4); however, the bias in Wk2-Wk4 is larger than during 1999-2009, particularly in the highlatitude Southern Ocean region. The bias in the interannual variability of SWH during Wk1-Wk4 in 19792009 (Figs. S3 and S4) is similar to the results for the 

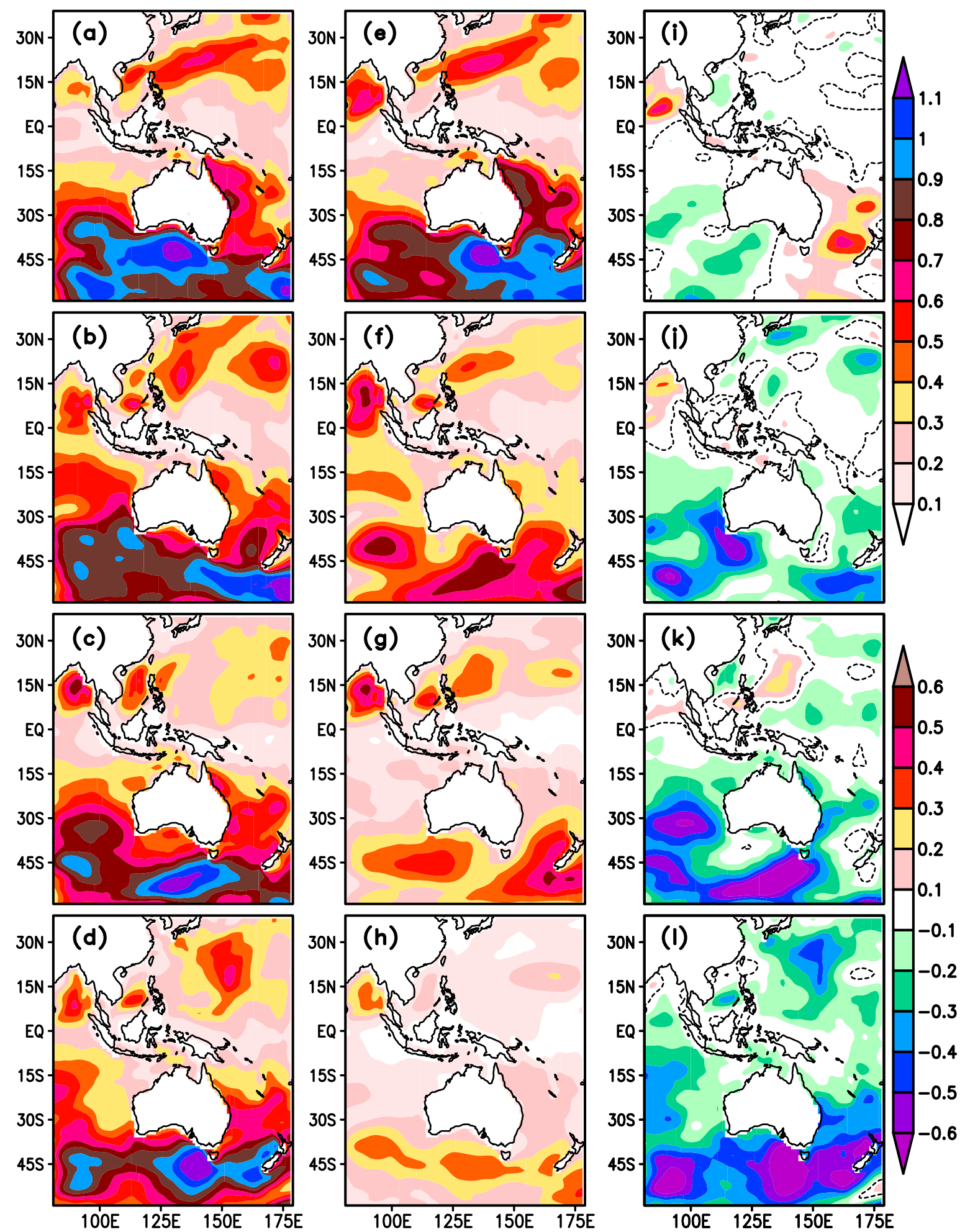

FIG. 6. As in Fig. 5, except for the May cases. 

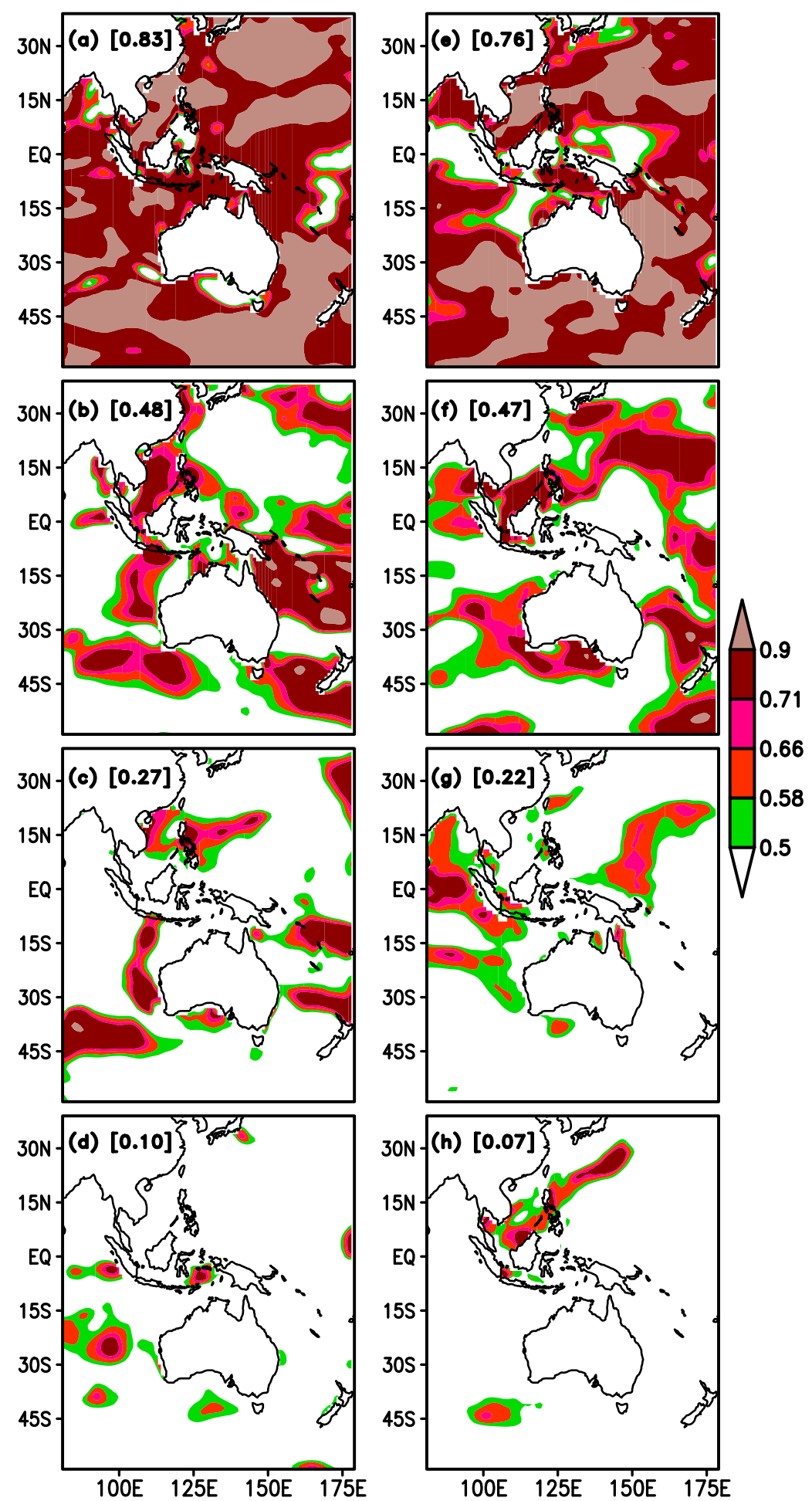

FIG. 7. (a),(b) Temporal anomaly correlation skill of SWH Wk1 WW3 forecasts made using daily CFSv2 retrospective simulations initialized each (left) January and (right) May for 1999-2009 for forcing WW3. (b),(d) As in (a),(b), but for Wk2. (c),(g) As in (a),(b), but for Wk3. (d), (h) As in (a),(b), but for Wk4. We have drawn correlation coefficients $(\mathrm{CC})$ at or above the $90 \%(\mathrm{CC}=0.50), 95 \%(\mathrm{CC}=0.58), 98 \%$ $(\mathrm{CC}=0.66)$, and $99 \%(\mathrm{CC}=0.71)$ significance levels. Spatial averages of the anomaly correlations over the analysis domain for 1999-2009 during the January (May) initialization weeks 1-4 are mentioned in bracket in each panel. 

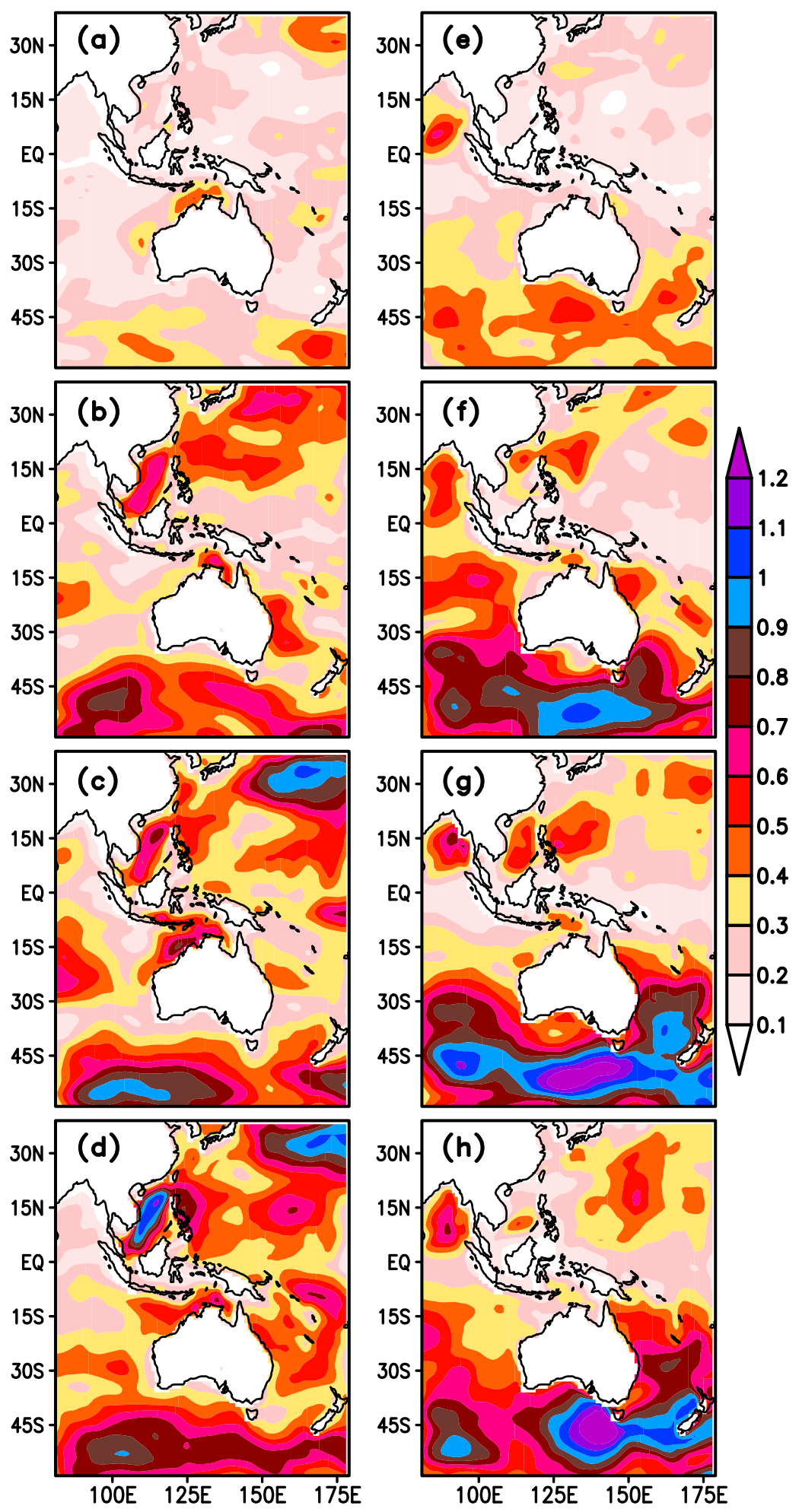

FIG. 8. As in Fig. 7, but for RMSEs. 
1999-2009 (Figs. 5 and 6) period. For the period 19792009 (31 yr), the correlation values for the $90 \%, 95 \%$, $98 \%$, and $99 \%$ significance levels are $0.30,0.35,0.41$, and 0.45 , respectively. The prediction skill of SWH is significantly higher in $\mathrm{Wk} 2$ and $\mathrm{Wk} 3$ for both the January and May cases using CFSv2_rev (Fig. 9). The spatial average of the anomaly correlation (SA-AC) over the analysis domain in the January (May) cases for weeks $1-4$ are 0.89 (0.81), 0.64 (0.58), 0.28 (0.24), and $0.18(0.08)$. The SA-AC during Wk2 in 1979-2009 is higher than for the period 1999-2009 (see Fig. 7; SA-SC values given in brackets) in both January and May cases. Other aspects of the SWH reforecasts made with CFSv2_rev for the 1979-2009 period are discussed in a separate paper.

\section{d. Spatial pattern anomaly correlation of SWH}

The interannual skill of the model can also be assessed using the spatial correlation and RMSE for each year (1999-2009) separately. Figures 10a,b show the spatial anomaly correlation (SAC) during each year for the predicted SWH in the January and May cases, respectively. The SAC skill for SWH during Wk1 and Wk2 is higher than for $\mathrm{Wk} 3$ and $\mathrm{Wk} 4$ in almost all years. It is notable that the SAC for Wk3 is high in several years. For the January (May) cases, there are 8 (9) yr out of 10 (11) yr in which the Wk3 SAC is positive. It is necessary to mention that the prediction skill of SWH in Wk4 is insignificant in both cases. Consistent with this result, the RMSEs in each year for Wk3 and Wk4 are higher than for Wk1 and Wk2 in both the January and May cases (not shown).

\section{Categorical forecast skill for dichotomous forecasts}

Categorical (dichotomous) forecast skill (Wilks 1995, 233-390; Shukla et al. 2011, 2013) refers to the ability of the model to predict events falling into (two) distinct categories. For this analysis, the forecasts are divided into two classes: rare events and normal events. As is the common practice, a rare event is defined as one in which the value is outside the range of \pm 1 standard deviation, and a normal event is one for which the value lies within 1 standard deviation of the mean. To evaluate the categorical forecast skill in the present study, weekly mean data were normalized by dividing each value by its own weekly standard deviation, so that the criterion for a rare event is satisfied when the modulus of the normalized observed SWH exceeds 1 . We have calculated the accuracy, bias, probability of detection (POD), false alarm ratio (FAR), probability of false detection (POFD), and threat score (TS) statistics following Wilks
(1995, 233-390; see also Shukla et al. 2011, 2013). Taking advantage of the natural geographical divisions of the WP-IO region, we have defined six regional time series indices of area-averaged SWH for which the areas are defined in Table 1 and shown in Fig. 11. The indices defined thus are averages in the SO, SIO, SWP, SCS, NWP, and BOB. We have used the same methodology to calculate contingency tables of categorical forecasts of rare events (not shown) and the dichotomous forecast skill (Tables 2 and 3) for the January and May cases, respectively, as discussed in Shukla et al. (2011, 2013, and papers cited therein).

In the January cases (Table 2), the accuracy of the mean of weeks 1 and 2 (Wk1-2) exceeds 0.70 in the SWP, SO, SIO, and SCS regions. Since the Wk1-2 bias is greater than 1 in SIO, BOB, and NWP, it can be argued that the model overpredicts SWH in the early part of the forecast in these regions. For the mean of weeks 3 and 4 (Wk3-4), the accuracy exceeds 0.50 for all regions except SCS and BOB. Since the Wk3-4 bias is less than 1 over all regions except NWP and BOB, the model apparently underpredicts $\mathrm{SWH}$ in the later part of the forecast. The POD is larger for Wk1-2 as compared with Wk3-4 in all regions. The FAR is a minimum for Wk1-2 in the SWP, SO, and SCS regions. For SR and SIO, the Wk3-4 FAR is 0.50 but it is larger for Wk3-4 in the SWP, SCS, NWP, and BOB regions, so the rate of failure to predict rare events is higher for $\mathrm{Wk} 3-4$ as compared to Wk1-2 in these regions. The POFD is small for SWP, $\mathrm{SO}$, and SCS in Wk1-2, implying that the fraction of "events" that were incorrectly forecast is small (Shukla et al. 2011, 2013). The POFD for Wk3-4 is also small in the SOR and SWP regions. Higher values of the TS for Wk1-2 in the SWP, SO and SCS regions indicate that CFSv2-WW3 is better in these regions at predicting rare events than in other regions. The TSs for Wk3-4 are also higher in the SO, SIO, and SCS regions. This analysis shows that CFSv2-WW3 is able to predict rare events in the SWP, SO, and SCS regions for $\mathrm{Wk} 1-2$, and in SO, SIO and SCS for Wk3-4 in the January cases.

In the May cases (Table 3), many of the same conclusions can be drawn from an analysis of the categorical skill of predicting rare SWH events. For SIO, SWP, and SCS, the Wk1-2 accuracy exceeds 0.82 . Since the bias is greater than 1 for Wk1-2 in SWP, SCS, and BOB, and in SCS for Wk3-4, it can be argued that CFSv2-WW3 overpredicts SWH. But it is observed that the bias is 1.0 for Wk3-4 over the NWP and BOB regions. The Wk3-4 accuracy exceeds 0.50 for all regions except BOBR. The Wk1-2 POD is larger than in Wk3-4 in all regions. The POD is high for Wk1-2 in SWP and SCS. The POD values for Wk3-4 are also reasonably high for SO and NWP. The FAR is 0.17 in SIO for Wk1-2. The FAR is 

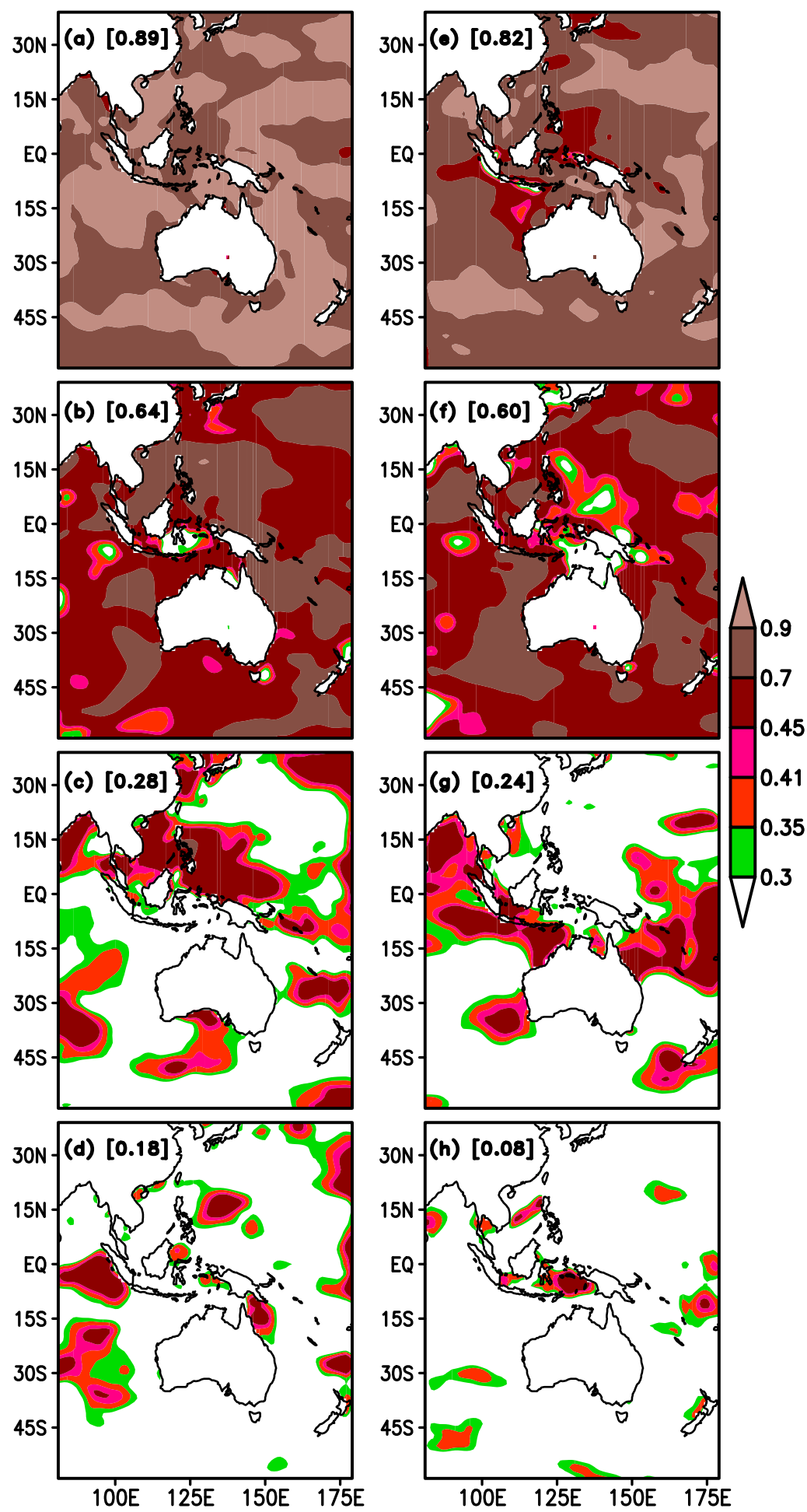

FIG. 9. As in Fig. 7, but for 1979-2009. We have drawn CCs at or above the $90 \%$ (CC $=$ $0.30), 95 \%(\mathrm{CC}=0.35), 98 \%(\mathrm{CC}=0.41)$, and $99 \%(\mathrm{CC}=0.45)$ signficance levels. 

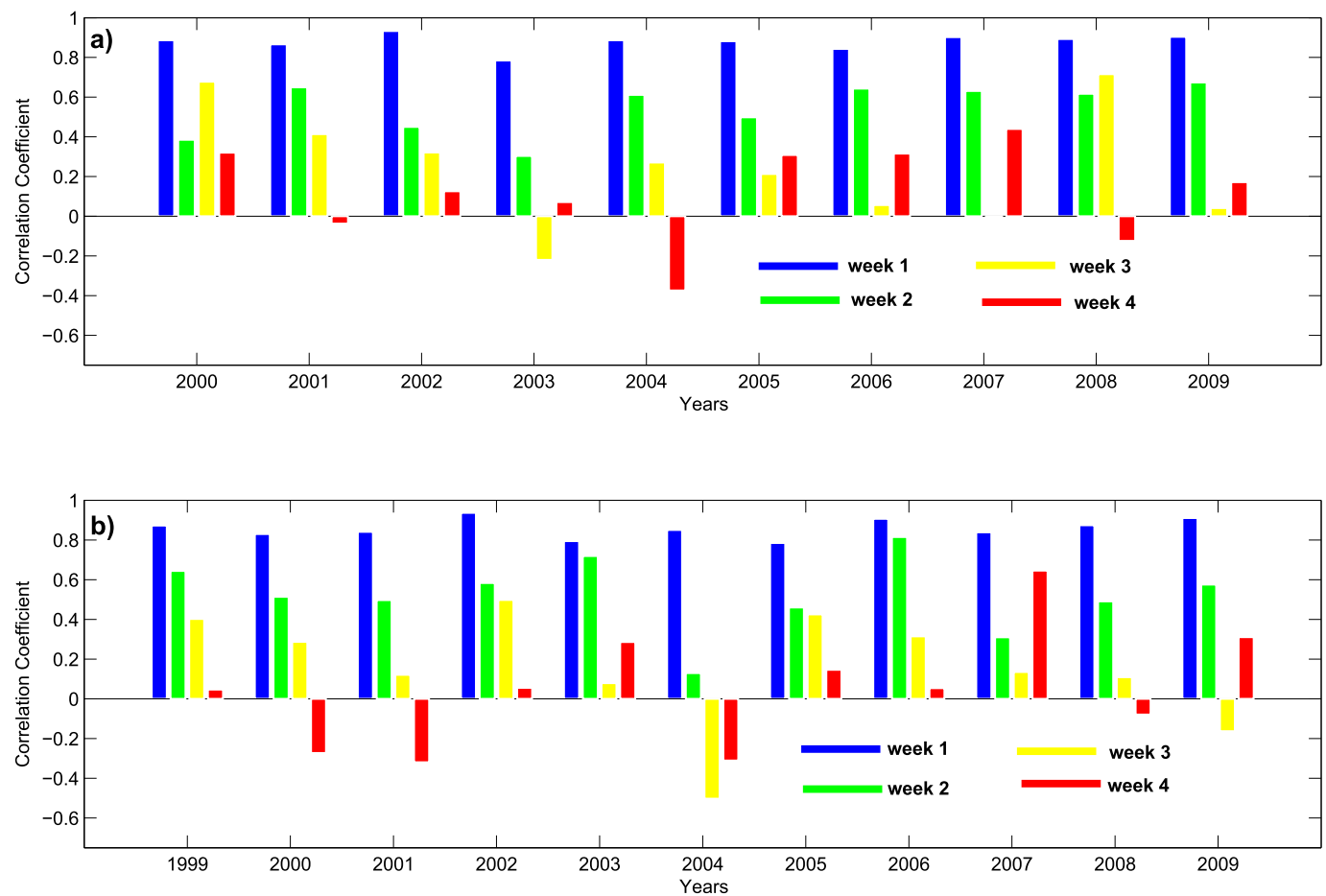

FIG. 10. (a) SAC of SWH for January cases for each year. The SACs for Wk1-Wk4 are plotted in blue, green, yellow and red, respectively. (b) As in (a) but for the May cases.

larger in all regions for $\mathrm{Wk} 3-4$ than for $\mathrm{Wk} 1-2$, so it may be concluded that the failure rate of predicting rare $\mathrm{SWH}$ events is larger for Wk3-4 than for Wk1-2. The POFD for Wk1-2 is low in SCS, SIO, and SWP, which suggests that the fraction of "events" that were incorrectly predicted is small. The POFD for Wk3-4 is also smaller for NWP and SO. The Wk1-2 TSs are high in the SIO, SWP, and SCS regions, which indicates that CFSv2WW3 is better at predicting rare events in these regions. The TS values for Wk3-4 are also higher for NWP and SO. The SO and NWP regions for Wk1-2 have about the same skill scores, implying that these two subregions are equivalent when predicting rare events (Shukla et al. 2011, 2013). The analysis indicates that CFSv2-WW3 is able to predict rare events in SIO, SWP, and SCS for Wk1-2, and in NWP and SO for Wk3-4 in the May cases.

\section{Summary and discussion}

In this study, we examined the skill of CFSv2-WW3 in predicting SWH at lead times of up to 4 weeks over the Indo-Pacific Ocean region. We forced the WW3 model with daily $10-\mathrm{m}$ winds from the CFSR, a thirdgeneration reanalysis, and from the CFSv2 NMME retrospective forecasts initialized in January and May for the period 1999-2009. The retrospective forecasts include 42-day lead time and all leads were used to force WW3. All the forecasts are made with 10-member lagged ensembles to provide a more robust estimate of the forecast.

The CFSv2 predicts the magnitude and direction of $10-\mathrm{m}$ wind over the SO, NCWP, SCS, and BOB regions in Wk1-Wk4 in both January and May cases. Quantitatively, however, the model has a negative bias over the BOB, SCS, and SO regions, with a 10-m wind speed deficit of up to $1 \mathrm{~m} \mathrm{~s}^{-1}$, and a positive bias in the NCWP and southern Pacific Ocean regions in Wk1 of the January cases. There are systematic biases in Wk1-Wk3 of the May cases; for example, a positive bias is found over the BOB region, as well as over the northern and southern western Pacific Ocean, mainly around $23^{\circ} \mathrm{N}$ and $45^{\circ} \mathrm{S}$, respectively. The magnitude of the biases increases with lead time in both the January and May cases.

TABLE 1. Geographical extent of various SWH indices.

\begin{tabular}{lc}
\hline \multicolumn{1}{c}{ Region } & Area averaged \\
\hline Southern Ocean (SO) & $59^{\circ}-39^{\circ} \mathrm{S}, 81^{\circ}-179^{\circ} \mathrm{E}$ \\
Southern Indian Ocean (SIO) & $32^{\circ}-12^{\circ} \mathrm{S}, 81^{\circ}-130^{\circ} \mathrm{E}$ \\
Southern western Pacific (SWP) & $32^{\circ}-12^{\circ} \mathrm{S}, 150^{\circ}-179^{\circ} \mathrm{E}$ \\
South China Sea (SCS) & $0^{\circ}-33^{\circ} \mathrm{N}, 104^{\circ}-121^{\circ} \mathrm{E}$ \\
Northern western Pacific (NWP) & $0^{\circ}-39^{\circ} \mathrm{N}, 125^{\circ}-179^{\circ} \mathrm{E}$ \\
Bay of Bengal (BOB) & $0^{\circ}-29^{\circ} \mathrm{N}, 81^{\circ}-98^{\circ} \mathrm{E}$ \\
\hline
\end{tabular}




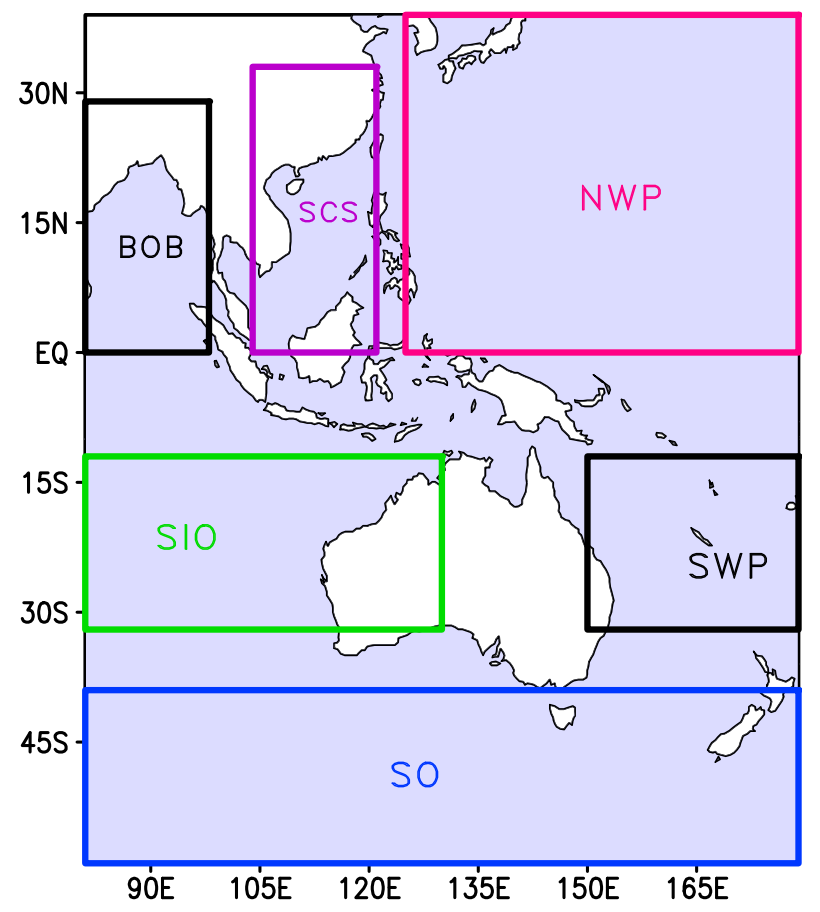

FIG. 11. The spatial locations of the six subdivisions listed in Table 1.

The CFSv2 wind forecasts are realistic enough to reproduce all of the major features of SWH over the Indo-Pacific basin at 3-4-week lead times when used to force the WW3 ocean wave model. The interannual variability of SWH anomalies is well captured in Wk1, but there are biases in the magnitude of the variability of SWH that significantly increase with lead time in both the January and May cases. It is likely that this is related to the lead-time-dependent bias in interannual variability of weekly mean $10-\mathrm{m}$ winds, which grows weaker with lead time in CFSv2.

In forecasts of up to 2-week lead time, the temporal anomaly correlation (TAC) of the SWH anomalies is significantly higher than the longer-lead forecasts, with some regional variability in skill. During $\mathrm{Wk} 4$, the temporal anomaly correlation is significant over the southern Indian Ocean in the January cases, and the South China Sea and northern western Pacific Ocean in the May cases. The RMSE for Wk3-4 is higher than for Wk1-2. The spatial anomaly correlation (SAC) for SWH during Wk1-2 is higher than in Wk3-4 in almost all years. The SAC for $\mathrm{Wk} 3$ is high in several of the years evaluated.

On the basis of categorical forecast verification, the CFSv2-WW3 model is shown to be able to predict rare events over the SWP, SO, and SCS subdomains for Wk1-2; over the SO, SIO, and SCS regions for Wk3-4 in January cases; over the SIO, SWP, and SCS regions
TABLE 2. Categorical skill scores for all subdomains for January ICs. For each domain, the first row is for $\mathrm{Wk} 1-4$, the center row (boldface) is for Wk1-2, and the last row (italics) is for Wk3-4. We have chosen six regions (Fig. 11): SO, SIO, SWP, SCS, NCWP, and BOB. The accuracy, bias, POD, FAR, POFD, and TS are shown.

\begin{tabular}{lcccccc}
\hline \hline Jan & Accuracy & Bias & POD & FAR & POFD & TS \\
\hline SO & 0.73 & 0.92 & 0.54 & 0.42 & 0.19 & 0.39 \\
& $\mathbf{0 . 8 0}$ & $\mathbf{1 . 0 0}$ & $\mathbf{0 . 6 7}$ & $\mathbf{0 . 3 3}$ & $\mathbf{0 . 1 4}$ & $\mathbf{0 . 5 0}$ \\
& 0.65 & 0.86 & 0.43 & 0.50 & 0.23 & 0.30 \\
SIO & 0.65 & 1.00 & 0.50 & 0.50 & 0.27 & 0.33 \\
& $\mathbf{0 . 7 0}$ & $\mathbf{1 . 3 3}$ & $\mathbf{0 . 6 7}$ & $\mathbf{0 . 5 0}$ & $\mathbf{0 . 2 9}$ & $\mathbf{0 . 4 0}$ \\
& 0.60 & 0.75 & 0.38 & 0.50 & 0.25 & 0.27 \\
SWP & 0.73 & 0.75 & 0.42 & 0.44 & 0.14 & 0.32 \\
& $\mathbf{0 . 9 0}$ & $\mathbf{1 . 0 0}$ & $\mathbf{0 . 8 0}$ & $\mathbf{0 . 2 0}$ & $\mathbf{0 . 0 7}$ & $\mathbf{0 . 6 7}$ \\
& 0.55 & 0.57 & 0.14 & 0.75 & 0.23 & 0.10 \\
SCS & 0.56 & 0.93 & 0.44 & 0.53 & 0.33 & 0.29 \\
& $\mathbf{0 . 7 0}$ & $\mathbf{1 . 0 0}$ & $\mathbf{0 . 6 3}$ & $\mathbf{0 . 3 8}$ & $\mathbf{0 . 2 5}$ & $\mathbf{0 . 4 5}$ \\
& 0.45 & 0.88 & 0.25 & 0.71 & 0.42 & 0.15 \\
NWP & 0.55 & 1.17 & 0.33 & 0.71 & 0.36 & 0.18 \\
& $\mathbf{0 . 6 0}$ & $\mathbf{1 . 3 3}$ & $\mathbf{0 . 5 0}$ & $\mathbf{0 . 6 3}$ & $\mathbf{0 . 3 6}$ & $\mathbf{0 . 2 7}$ \\
& 0.50 & 1.00 & 0.17 & 0.83 & 0.36 & 0.09 \\
BOB & 0.48 & 1.07 & 0.29 & 0.73 & 0.43 & 0.16 \\
& $\mathbf{0 . 5 5}$ & $\mathbf{1 . 1 7}$ & $\mathbf{0 . 3 3}$ & $\mathbf{0 . 7 1}$ & $\mathbf{0 . 3 6}$ & $\mathbf{0 . 1 8}$ \\
& 0.40 & 1.00 & 0.25 & 0.75 & 0.50 & 0.14 \\
\hline
\end{tabular}

for Wk1-2; and over the NWP and SO regions for Wk3-4 in May cases.

Overall, the performance of the CFSv2-WW3 forecasts of SWH for lead times of up to 4 weeks is as expected, with diminishing skill as lead time increases. There is little seasonal dependence of the forecast skill as noted in the similarities of the skill in the January and May cases. There are some regions for which the SWH forecast skill may be useful even at 3-4-week lead times.

TABLE 3. Categorical skill scores for all subdomains for the May cases. Rows and fonts for each domain are as in Table 2.

\begin{tabular}{lcccccc}
\hline \hline May & Accuracy & Bias & POD & FAR & POFD & TS \\
\hline SO & 0.66 & 0.80 & 0.40 & 0.50 & 0.21 & 0.29 \\
& $\mathbf{0 . 7 7}$ & $\mathbf{0 . 8 5}$ & $\mathbf{0 . 5 7}$ & $\mathbf{0 . 3 3}$ & $\mathbf{0 . 1 3}$ & $\mathbf{0 . 4 4}$ \\
\multirow{4}{*}{ SIO } & 0.55 & 0.75 & 0.25 & 0.67 & 0.29 & 0.17 \\
& 0.66 & 0.80 & 0.40 & 0.50 & 0.21 & 0.29 \\
& $\mathbf{0 . 8 2}$ & $\mathbf{0 . 7 5}$ & $\mathbf{0 . 6 3}$ & $\mathbf{0 . 1 7}$ & $\mathbf{0 . 0 7}$ & $\mathbf{0 . 5 6}$ \\
SWP & 0.50 & 0.86 & 0.14 & 0.83 & 0.33 & 0.08 \\
& 0.66 & 1.07 & 0.50 & 0.53 & 0.27 & 0.32 \\
& $\mathbf{0 . 8 2}$ & $\mathbf{1 . 2 9}$ & $\mathbf{0 . 8 6}$ & $\mathbf{0 . 3 3}$ & $\mathbf{0 . 2 0}$ & $\mathbf{0 . 6 0}$ \\
SCS & 0.50 & 0.86 & 0.14 & 0.83 & 0.33 & 0.08 \\
& 0.77 & 1.28 & 0.43 & 0.67 & 0.16 & 0.23 \\
& $\mathbf{0 . 9 5}$ & $\mathbf{1 . 5 0}$ & $\mathbf{1 . 0 0}$ & $\mathbf{0 . 3 3}$ & $\mathbf{0 . 0 5}$ & $\mathbf{0 . 6 7}$ \\
NWP & 0.59 & 1.20 & 0.20 & 0.83 & 0.29 & 0.10 \\
& 0.75 & 0.92 & 0.50 & 0.46 & 0.16 & 0.35 \\
& $\mathbf{0 . 7 7}$ & $\mathbf{0 . 8 5}$ & $\mathbf{0 . 5 7}$ & $\mathbf{0 . 3 3}$ & $\mathbf{0 . 1 3}$ & $\mathbf{0 . 4 4}$ \\
BOB & 0.73 & 1.00 & 0.40 & 0.60 & 0.18 & 0.25 \\
& 0.54 & 1.17 & 0.25 & 0.79 & 0.34 & 0.13 \\
& $\mathbf{0 . 6 4}$ & $\mathbf{1 . 4 0}$ & $\mathbf{0 . 4 0}$ & $\mathbf{0 . 7 1}$ & $\mathbf{0 . 2 9}$ & $\mathbf{0 . 2 0}$ \\
& 0.45 & 1.00 & 0.14 & 0.86 & 0.40 & 0.08 \\
\hline
\end{tabular}


Further research on how to improve low-level wind forecasts over the western Pacific and Indian Ocean region would likely benefit the subseasonal prediction of SWH.

Acknowledgments. Funding for this study was provided by a grant from the Office of Naval Research (ONR; N000141210995). The CFSR and CFSv2 retrospective analysis data were obtained from the NOAA/ National Centers for Environmental Information NOMADS server, for which access is gratefully acknowledged. The WW3 model code made available by NCEP is also gratefully acknowledged. We would like to thank Dr. Chul-Su Shin for conducting CFSv2_rev retrospective simulations for the period 1979-2009 analyzed in this paper. This work used the Extreme Science and Engineering Discovery Environment (XSEDE). The authors are grateful to four anonymous reviewers for their constructive comments and suggestions, which improved the quality of the manuscript significantly.

\section{REFERENCES}

Abhilash, S., and Coauthors, 2015: Improved spread-error relationship and probabilistic prediction from the CFS-based Grand Ensemble Prediction System. J. Appl. Meteor. Climatol., 54, 1569-1578, doi:10.1175/JAMC-D-14-0200.1.

Alexander, M. A., 1992: Midlatitude atmosphere-ocean interaction during El Niño. Part I: The North Pacific Ocean. J. Climate, 5, 944-958, doi:10.1175/1520-0442(1992)005<0944: MAIDEN>2.0.CO;2.

Baldwin, M. P., and T. J. Dunkerton, 2001: Stratospheric harbingers of anomalous weather regimes. Science, 294, 581-584, doi:10.1126/science.1063315.

Barnston, A. G., S. Li, S. J. Mason, D. G. DeWitt, L. Goddard, and X. Gong, 2010: Verification of the first 11 years of IRI's seasonal climate forecasts. J. Appl. Meteor. Climatol., 49, 493520, doi:10.1175/2009JAMC2325.1.

Becker, E., H. Van den Dool, and Q. Zhang, 2014: Predictability and forecast skill in NMME. J. Climate, 27, 5891-5906, doi:10.1175/JCLI-D-13-00597.1.

Behringer, D. W., 2005: The Global Ocean Data Assimilation System (GODAS) at NCEP. Preprints, 11th Symp. on Integrated Observing and Assimilation Systems for the Atmosphere, Oceans, and Land Surface (IOAS-AOLS), San Antonio, TX, Amer. Meteor. Soc., 3.3. [Available online at https://ams.confex. com/ams/87ANNUAL/techprogram/paper_119541.htm.]

Chawla, A., H. L. Tolman, J. L. Lanson, E. M. Devaliere, and V. M. Gerald, 2009: Validation of a multi-grid WAVEWATCH IIITM modeling system. NOAA/MMAB Contribution 281, $15 \mathrm{pp}$. [Available online at http://polar.ncep.noaa.gov/mmab/ papers/tn281/multi_hindanalysis.pdf.]

Chu, P. C., Y. Qi, Y. Chen, P. Shi, and Q. Mao, 2004: South China Sea wind-wave characteristics. Part I: Validation of WAVEWATCHIII using TOPEX/Poseidon data. J. Atmos. Oceanic Technol., 21, 1718-1733, doi:10.1175/JTECH1661.1.

Fan, Y., S.-J. Lin, I. M. Held, Z. Yu, and H. L. Tolman, 2012: Global ocean surface wave simulation using a coupled atmosphere-wave model. J. Climate, 25, 6233-6252, doi:10.1175/ JCLI-D-11-00621.1.

Goswami, B. B., M. Deshpande, P. Mukhopadhyay, S. K. Saha, S. A. Rao, R. Murthugudde, and B. N. Goswami, 2014: Simulation of monsoon intraseasonal variability in NCEP CFSv2 and its role on systematic bias. Climate Dyn., 43, 2725-2745, doi:10.1007/s00382-014-2089-5.

Griffies, S. M., M. J. Harrison, R. C. Pacanowski, and A. Rosati, 2004: A technical guide to MOM4. GFDL Ocean Group Tech. Rep. 5, 342 pp. [Available online at https://www.gfdl.noaa.gov/ bibliography/related_files/smg0301.pdf.]

Guo, Z., P. A. Dirmeyer, T. DelSole, and R. D. Koster, 2012: Rebound in atmospheric predictability and the role of the land surface. J. Climate, 25, 4744-4749, doi:10.1175/ JCLI-D-11-00651.1.

Hanson, J. L., B. A. Tracy, H. L. Tolma, and D. R. Scott, 2009: Pacific hindcast performance of three numerical wave models. J. Atmos. Oceanic Technol., 26, 1614-1633, doi:10.1175/ 2009JTECHO650.1.

Hartmann, D. L., 2015: Pacific sea surface temperature and the winter of 2014. Geophys. Res. Lett., 42, 1894-1902, doi:10.1002/ 2015 GL063083.

Hoskins, B., 2013: The potential for skill across the range of the seamless weather-climate prediction problem: A stimulus for our science. Quart. J. Roy. Meteor. Soc., 139, 573-584, doi:10.1002/qj.1991.

— , and D. J. Karoly, 1981: The steady linear response of a spherical atmosphere to thermal and orographic forcing. J. Atmos. Sci., 38, 1179-1196, doi:10.1175/1520-0469(1981)038<1179: TSLROA $>2.0 . \mathrm{CO} ; 2$.

— , and T. Woollings, 2015: Persistent extratropical regimes and climate extremes. Curr. Climate Change Rep., 1, 115-124, doi:10.1007/s40641-015-0020-8.

Huang, B., and Coauthors, 2015: Climate drift of AMOC, North Atlantic salinity and Arctic sea ice in CFSv2 decadal predictions. Climate Dyn., 44, 559-583, doi:10.1007/s00382-014-2395-y.

Hudson, D., O. Alves, H. H. Hendon, and A. G. Marshall, 2011: Bridging the gap between weather and seasonal forecasting: Intraseasonal forecasting for Australia. Quart. J. Roy. Meteor. Soc., 137, 673-689, doi:10.1002/qj.769.

IPCC, 2007: Climate Change 2007: The Physical Science Basis. Cambridge University Press, 996 pp.

Janssen, P. A. E. M., J. D. Doyle, J. Bidlot, B. Hansen, L. Isaksen, and P. Viterbo, 2002: Impact and feedback of ocean waves on the atmosphere. Atmosphere-Ocean Interactions, Vol. I, W. Perrie, Ed., Advances in Fluid Mechanics, Vol. 33, WIT Press, 155-197.

Jung, T., M. J. Miller, and T. N. Palmer, 2010: Diagnosing the origin of extended-range forecast errors. Mon. Wea. Rev., 138, 2434 2446, doi:10.1175/2010MWR3255.1.

Kirtman, B. P., and Coauthors, 2014: The North American Multimodel Ensemble: Phase-1 seasonal-to-interannual prediction; phase-2 toward developing intraseasonal prediction. Bull. Amer. Meteor. Soc., 95, 585-601, doi:10.1175/BAMS-D-12-00050.1.

Komen, G. J., L. Cavaleri, M. Donelan, K. Hasselmann, S. Hasselmann, and P. A. E. M. Janssen, 1994: Dynamics and Modeling of Ocean Waves. Cambridge University Press, 520 pp.

Koster, R. D., and Coauthors, 2011: The second phase of the Global Land-Atmosphere Coupling Experiment: Soil moisture contributions to subseasonal forecast skill. J. Hydrometeor., 12, 805-822, doi:10.1175/2011JHM1365.1.

Lin, H., and G. Brunet, 2009: The influence of the Madden-Julian oscillation on Canadian wintertime surface air temperature. Mon. Wea. Rev., 137, 2250-2262, doi:10.1175/2009MWR2831.1. 
Lopez, H., and B. P. Kirtman, 2016: Investigating the seasonal predictability of significant wave height in the West Pacific and Indian Oceans. Geophys. Res. Lett., 43, 3451-3458, doi:10.1002/ 2016GL068653

Marshall, A. G., H. H. Hendon, T. H. Durrant, and M. A. Hemer, 2015: Madden-Julian oscillation impacts on global ocean surface waves. Ocean Modell., 96, 136-147, doi:10.1016/ j.ocemod.2015.06.002.

Mirzaei, A., F. Tangang, L. Juneng, M. A. Mustapha, M. L. Husain, and M. F. Akhir, 2013: Wave climate simulation for southern region of the South China Sea. Ocean Dyn., 63, 961-977, doi:10.1007/s10236-013-0640-2.

National Research Council, 2010: Assessment of Intraseasonal to Interannual Climate Prediction and Predictability. National Academies Press, 192 pp., doi:10.17226/12878.

Saha, S., and Coauthors, 2010: The NCEP Climate Forecast System Reanalysis. Bull. Amer. Meteor. Soc., 91, 1015-1057, doi:10.1175/ 2010BAMS3001.1.

—_, and Coauthors, 2014: The NCEP Climate Forecast System version 2. J. Climate, 27, 2185-2208, doi:10.1175/ JCLI-D-12-00823.1.

Saha, S. K., and Coauthors, 2014: Improved simulation of Indian summer monsoon in latest NCEP climate forecast system free run. Int. J. Climatol., 34, 1628-1641, doi:10.1002/joc.3791.

Scaife, A. A., J. R. Knight, G. K. Vallis, and C. K. Folland, 2005: A stratospheric influence on the winter NAO and North Atlantic surface climate. Geophys. Res. Lett., 32, L18715, doi:10.1029/ 2005 GL023226.

— pean and North American winters. Geophys. Res. Lett., 41, 2514-2519, doi:10.1002/2014GL059637.

Shukla, R. P., and J. L. Kinter, 2014: Simulation of the Asian monsoon using a regionally coupled-global climate model. Climate Dyn., 44, 827-843, doi:10.1007/s00382-014-2188-3.

—_, and B. Huang, 2015: Mean state and interannual variability of the Indian summer monsoon simulation by NCEP CFSv2. Climate Dyn., 46, 3845-3864, doi:10.1007/s00382-015-2808-6.

$\longrightarrow$, K. C. Tripathi, S. Mukherjee, A. C. Pandey, and I. M. L. Das, 2011: Improved seasonal predictability skill of the DEMETER models for central Indian summer monsoon rainfall. Challenges and Opportunities in Agrometeorology, S. D. Attri et al., Eds., Springer-Verlag, 139-147.

_ S. Rai, and A. C. Pandey, 2013: Southern and tropical Indian Ocean SST: A possible predictor of winter monsoon rainfall over South India. Atmos. Climate Sci., 3, 440-449, doi:10.4236/ acs.2013.34045.

The WAMDI Group, 1988: The WAM model-A third generation ocean wave prediction model. J. Phys. Oceanogr., 18, 1775-1810, doi:10.1175/1520-0485(1988)018<1775: TWMTGO $>2.0 . \mathrm{CO} ; 2$.

Tolman, H. L., 1998: Validation of a new global wave forecast system at NCEP. Ocean Wave Measurements and Analysis, B. L. Edge and J. M. Helmsley, Eds., ASCE, 777-786.

- 2002: Validation of WAVEWATCH III version 1.15 for a global domain. NCEP/NOAA/NWS. NCEP Tech. Note 213, 33 pp. [Available online at http://polar.ncep.noaa.gov/mmab/ papers/tn213/OMB_213.pdf.]

, 2009: User manual and system documentation of WAVEWATCH III ${ }^{\mathrm{TM}}$ version 3.14. NOAA/NWS/NCEP/ MMAB Tech. Note 276, 194 pp. + appendixes. [Available online at http://polar.ncep.noaa.gov/mmab/papers/tn276/MMAB_276.pdf.]

_, B. Balasubramaniyan, L. D. Burroughs, D. V. Chalikov, Y. Y. Chao, H. S. Chen, and V. M. Gerald, 2002: Development and implementation of wind-generated ocean surface wave models at NCEP. Wea. Forecasting, 17, 311-333, doi:10.1175/ 1520-0434(2002)017<0311:DAIOWG >2.0.CO;2.

Vinoth, J., and I. R. Young, 2011: Global estimates of extreme wind speed and wave height. J. Climate, 24, 1647-1665, doi:10.1175/ 2010JCLI3680.1.

Vitart, F., 2014: Evolution of ECMWF sub-seasonal forecast skill scores. Quart. J. Roy. Meteor. Soc., 140, 1889-1899, doi:10.1002/ qj.2256.

Wang, W., M. P. Hung, S. J. Weaver, A. Kumar, and X. Fu, 2014: MJO prediction in the NCEP Climate Forecast System version 2. Climate Dyn., 42, 2509-2520, doi:10.1007/ s00382-013-1806-9.

Wilks, D. S., 1995: Statistical Methods in Atmospheric Sciences: An Introduction. Academic Press, 467 pp.

Woolf, D. K., P. G. Challenor, and P. D. Cotton, 2002: Variability and predictability of the North Atlantic wave climate. Geophys. Res. Lett., 107, 3145, doi:10.1029/2001JC001124.

World Meteorological Organization, 2013: Sub-seasonal to seasonal prediction research implementation plan. WMO, $64 \mathrm{pp}$. [Available online at http://www.wmo.int/pages/prog/arep/ wwrp/new/documents/S2S_Implem_plan_en.pdf.]

Young, I. R., 1999: Seasonal variability of the global ocean wind and wave climate. Int. J. Climatol., 19, 931-950, doi:10.1002/ (SICI)1097-0088(199907)19:9<931::AID-JOC412>3.0.CO;2-O. 